\title{
Carriage of Staphylococcus aureus in the elderly
}

\author{
R. M. Parnaby, G. O'Dwyer, H. A. Monsey and M. S. Shafi \\ Central Middlesex PHL and NHS Trust, Acton Lane, London, NW10 7NS, \\ $U K$
}

Received 27 September 1995; revised manuscript accepted 6 March 1996

\begin{abstract}
Summary: The point prevalence and incidence of Staphylococcus aureus (methicillin-sensitive and -resistant) carriage by inpatients on acute elderly care wards was estimated. The relationship to body site and to previous admissions to hospital or other institutions was determined. Fifty-five patients were included in the point prevalence study and 136 in the incidence study, which was performed over a two-month period. One in three patients carried $S$. aureus and 1 in 20 was infected. The incidence rate for MRSA was $2 \cdot 9 \%$. No endemic strain was found. Nostrils were signiticantly associated with carriage, and skin break isolates were significant in the point prevalence survey. Screening these sites alone would be most cost effective.
\end{abstract}

Keywords: Staphylococcus aureus; MRSA; elderly inpatients.

\section{Introduction}

Staphylococcus aureus continues to be a major cause of infection in hospitals. ${ }^{1}$ Strains of methicillin-resistant $S$. aureus (MRSA) were first reported in $1961^{2}$ and their emergence has hampered the eradication of staphylococcal cross infection. Numerous epidemics of nosocomial infection, associated with considerable morbidity and mortality, have been reported worldwide. ${ }^{3}$ Although MRSA are generally no more virulent than methicillin-sensitive S. aureus (MSSA) ${ }^{4}$ the treatment options for colonization or infection are limitcd. Trcatmont of hospital-acquired infection has severe personal impact on the patient and considerable cost implications for the hospital. ${ }^{5}$ The appearance of MRSA is associated with increased rates of hospital-acquired $S$. aureus infection overall. ${ }^{6}$ This study was, therefore, undertaken to:

(1) examine the overall carriage and infection rates of $S$. aureus, including MRSA in patients on acute elderly care wards; (2) evaluate whether such carriage relates to body site in order to adopt a rational approach to future screening; and (3) investigate whether carriage and infection rates were influenced by previous admissions to hospital or other institutions, as has been found elsewhere. ${ }^{7}$

Correspondence to: Dr R. M. Parnaby, Department of Microbiology, George Eliot Hospital, Nuneaton, Warwickshire, CV10 7DJ, UK. 


\section{Patients and methods}

\section{Point prevalence survey}

Inpatients on four acute elderly care wards were screened for $S$. aureus over four consecutive days in February 1994 (one ward per day). The sites sampled were nostrils, throat, axillae, perineum, indwelling urinary catheter site (if present) and skin breaks (if present). A questionnaire (see Appendix) to establish the hospital admission and residential history of the patient and risk factors for staphylococcal colonization was completed at the time of sampling.

\section{Incidence survey}

Consecutive admissions to the same wards during February and March 1994 were screened, within $24 \mathrm{~h}$ of admission, using the same protocol. Patients who were admitted after the weekend screen had been taken were screened on Monday morning.

\section{Laboratory procedures}

Swabs from one patient were inoculated together into 10\% salt Robertson's cooked-meat broth (Central Public I Iealth Laboratory) and incubated at $37^{\circ} \mathrm{C}$ aerobically for $48 \mathrm{~h}$. Subculture was made onto mannitol salt agar (Unipath), incubated at $37^{\circ} \mathrm{C}$ aerobically and examined at 24 and $48 \mathrm{~h}$. If positive, the patient was rescreened and these swabs processed separately. Identification of staphylococci was by Staphylase reagent (Unipath), DNAse testing (Oxoid) and tube coagulase. Methicillin testing was performed on diagnostic sensitivity testing agar (Oxoid) at $30^{\circ} \mathrm{C}$ overnight, using $25 \mu \mathrm{g}$ strips (Mast Diagnostics). Phage-typing was performed by the Staphylococcal Reference Laboratory (Central Public Health Laboratory).

\section{Results}

The demographics of the patient populations, in the two surveys, are summarized in Table I.

The point prevalence survey $(N=55)$ yielded $15(29 \%)$ isolates of MSSA and no MRSA. Three $(5 \cdot 5 \%)$ patients were clinically infected, one with cellulitis and two with infected varicose ulcers. Nine $(60 \%)$ patients were available for rescreening. Ten strains were typable and nine were single isolates. No clusters were identified.

The incidence survey $(N=136)$ yielded $48(35 \%)$ isolates of MSSA and four $(2.9 \%)$ isolates of MRSA. Five (3.7\%) were infected with MSSA (three with cellulitis, one with infected eczema and one with infected broken skin following a fall). No patient was infected with MRSA. Thirty (59\%) patients were available for rescreening. Table II records the phage-types by ward.

Neither survey found a significant relationship between MSSA or MRSA 
Table I. Patient population in point prevalance and incidence surveys on acute elderly care wards

\begin{tabular}{|c|c|c|c|c|}
\hline \multirow[t]{2}{*}{ Patient population } & \multicolumn{2}{|c|}{ Point prevalence } & \multicolumn{2}{|c|}{ Incidence } \\
\hline & $N=55$ & $\%$ & $N=136$ & $\%$ \\
\hline Male:female & $23: 32$ & $42: 58$ & $60: 76$ & $44: 56$ \\
\hline Agc rangc (mcdian) & $62-96$ & $(79)$ & $66-99$ & $(81)$ \\
\hline Emergency admissions & 50 & 91 & 133 & $97 \cdot 8$ \\
\hline \multicolumn{5}{|l|}{ Admitted from: } \\
\hline Own home & 43 & 78 & 108 & 80 \\
\hline Residential/warden aided & 6 & 11 & 16 & $11 \cdot 9$ \\
\hline Other ward $\mathrm{CMH}^{*}$ & 6 & 11 & 9 & $6 \cdot 7$ \\
\hline Other hospital & 0 & 0 & 2 & $1 \cdot 5$ \\
\hline \multicolumn{5}{|l|}{ Past admissions: } \\
\hline $\mathrm{CMH}^{*}$ previous month & 9 & $16 \cdot 4$ & 19 & $14 \cdot 1$ \\
\hline $\mathrm{CMH}^{*}$ preceding year & 23 & 42 & 41 & $29 \cdot 9$ \\
\hline Other institution last year & 5 & $9 \cdot 1$ & 22 & $16 \cdot 2$ \\
\hline Surgery in last year & 8 & $14 \cdot 5$ & 14 & $10 \cdot 3$ \\
\hline Infective diagnosis & 10 & 18 & 35 & $23 \cdot 6$ \\
\hline Catheterized before admission & 1 & $1 \cdot 8$ & 4 & 3 \\
\hline Catheterized at swabbing & 9 & $16 \cdot 4$ & 13 & $9 \cdot 6$ \\
\hline Skin breaks: & 24 & $43 \cdot 6$ & 61 & $44 \cdot 9$ \\
\hline Intra vascular device site & 8 & $14 \cdot 5$ & 42 & $31 \cdot 1$ \\
\hline Chronic ulcer & 10 & $18 \cdot 2$ & 15 & $5 \cdot 3$ \\
\hline Cellulitis & 3 & $5 \cdot 5$ & 7 & $5 \cdot 3$ \\
\hline Other skin breaks & 8 & $14 \cdot 5$ & 12 & $8 \cdot 8$ \\
\hline
\end{tabular}

* CMH denotes Central Middlesex Hospital.

carriage and place of residence, previous admission to hospital or other institution, surgery or urinary catheterization.

Nasal carriage of MSSA was significant in both surveys $N=7 / 9(78 \%)$, $P=0.01$ and $N=15 / 30(50 \%), P=0.018$, respectively. The incidence of nasal and skin brcak carriage of MRSA was significant $N=4 / 4(100 \%), P-$ 0.03 . Skin breaks yielded MSSA isolates significantly in the point prevalence survey $N=4 / 9(44 \%), P=0 \cdot 0003$.

\section{Discussion}

The unavailability of patients for a second screen after a positive isolate $(40 \%)$ was high. Our findings should be considered as a pilot study: the design has been satisfactorily tested and could be applied in any setting. The point prevalence and incidence populations were broadly similar. The former were more likely to have been admitted from another ward in our hospital and to have a urinary catheter in situ.

Although the numbers in our surveys were small, the significant findings were identified by Fisher's exact test (for small sample sizes), and do suggest that screening nostrils and skin breaks alone is most cost effective. On initial screen this would reduce the number of swabs used by at least four (price $8 \mathrm{p}$ per swab). On follow up, when swabs are processed separately, a 
Table II. Phage types of Staphylococcus aureus on four acute elderly care wards in the point prevalence survey. $\mathrm{P}$ values are included if more than one case has occurred on only one ward

\begin{tabular}{|c|c|c|c|c|}
\hline Phage type & Ward 1 & Ward 2 & Ward 3 & Ward 4 \\
\hline Not typable & $\begin{array}{l}6 \text { incl } 2 \\
\text { MRSA } \\
P=0 \cdot 29\end{array}$ & 2 & $\begin{array}{l}4 \text { incl } 1 \\
\text { MRSA } \\
P=0.72\end{array}$ & 2 \\
\hline Strain A & & $\begin{array}{c}4 \text { incl } 1 \\
\text { MRSA } \\
P=0.0009\end{array}$ & & \\
\hline Strain B & 2 & 2 & 2 & \\
\hline Strain C & 1 & & 2 & \\
\hline $\begin{array}{l}\text { Strain D } \\
\text { Strain E }\end{array}$ & 1 & 1 & & 2 \\
\hline $\begin{array}{l}\text { Strain F } \\
\text { Strain G }\end{array}$ & & & $\begin{array}{l}1 \\
1\end{array}$ & \\
\hline Strain $\mathrm{H}$ & & 1 & & \\
\hline $\begin{array}{l}\text { Strain I } \\
\text { Strain J }\end{array}$ & $P=\stackrel{2}{0.086}$ & & & 1 \\
\hline $\begin{array}{l}\text { Strain K } \\
\text { Strain L } \\
\text { Strain M } \\
\text { Strain N }\end{array}$ & 1 & & 1 & $P=\begin{array}{l}1 \\
1 \\
2 \\
0 \cdot 086 \\
1\end{array}$ \\
\hline
\end{tabular}

MRSA, methicillin-resistant Staphylococcus aureus.

decision must be made as to whether to screen nostrils and skin breaks only, (using one broth for enrichment per swab, and half a plate for isolation per broth), or whether to then perform a full screen, which would use at least four extra broths (price $54 \mathrm{p}$ per broth) and two extra plates per patient (price 27 p per plate). Previous work has indicated that over $80 \%$ of colonized patients are detected by nares culture alone ${ }^{8}$ which, taken in conjunction with our study, suggests that full screens are unnecessary except in specific cases when the index of suspicion is high but nose and skin break screening is negative. Targeting patients with urinary catheters is not worthwhile. Although we did not look at length of stay specifically, screening medium to long-stay patients with skin breaks (as represented by the point prevalence study) may be useful. ${ }^{2,9}$

Eighteen distinct phage types of $S$. aureus were identified across the two studies, and $18(31.6 \%)$ isolates were not typable. Of the four Strain A isolates on one ward, three were MSSA and one was MRSA. All of these patients had skin breaks. Two were admitted from one other ward in our hospital and two from the Day Hospital. Their dates of admission spanned one month. Three of the patients with MRSA were admitted from home and one from another ward. One had been in our hospital previously, and one in another hospital. Three had skin breaks. Two patients were on one ward and their dates of admission were a month apart. 
To facilitate infection control it would seem appropriate, therefore, to screen all elderly patients with skin breaks on admission for carriage of $S$. aureus in nares and skin break site.

We wish to thank Drs C. Cayley, B. Kaufman and D. McCrea for permission to study their patients, Dr S. Hussein for his help, and the Staphylococcal Reference Laboratory at the Central Public Health Laboratory for phage-typing the isolates.

\section{References}

1. Sheagren JN. Staphylococcus aureus. The persistent pathogen. N Engl I Med 1984; 110 : $1368-1373$

2. Jevons MP. 'Celbenin' resistant staphylococci. BMY 1961; i: 124-125.

3. Murphy S, Denman S, Bennett RG, Greenough WB, Lindsay J, Zelesnick LB. Methicillin resistant Staphylococcus aureus in a long-term care facility. $\mathscr{F} A G S$ 1992; 40: 213-217.

4. French GL, Cheng AFB, Ling MJL, Mo P, Donnan S. Hong Kong strains of methicillinresistant and methicillin-sensitive Staphylococcus aureus have similar virulence. $\mathcal{F}$ Hosp Infect 1990; 15: 117-125.

5. Richards J, Williams H, Warner M, Johnson $\Lambda$ P, Rcith S, Woodford N, Marples RR, George RC. Nosocomial spread of Staphylococcus aureus showing intermediate resistance to methicillin. 7 Hosp Infect 1993; 25: 91-96.

6. Boyce JM, White RL, Spruill EY. Impact of methicillin-resistant Staphylococcus aureus on the incidence of nosocomial staphylococcal infections. I Infect Dis 1983; 148: 763.

7. Muder RR, Brennan C, Wagener MM, Vickers RM, Rihs JD, Hancock GA, Yee YC et al. Methicillin resistant staphylococcal colonization and infection in a long-term care facility. Ann Intern Med 1991; 114: 107-112.

8. Sewell DL, Potter SA, Jacobson CM, Strausbaugh LJ, Ward 'I'T. Sensitivity of surveillance cultures for the detection of methicillin-resistant Staphylococcus aureus in a nursing-home-care unit. Diag Microbiol Infect Dis 1993; 17: 53-56.

9. Bradley SF, Terpenning MS, Ramsay MA, Zarins LT, Jorgensen KA, Sottile WS, Schaberg DR et al. Methicillin-resistant Staphylococcus aureus: colonization and infection in a long-term care facility. Ann Intern Med 1991; 115: 417-422.

\section{Appendix: Questionnaire}

Study number................ Hospital number.

Ward.

DOB

DOA

Elective/Emergency.

Admitted from

Reason for admission

Relevant medical conditions:

1

2

3

4

5

Previous admissions to $\mathrm{CMH}$ in last month? $\mathrm{Y} / \mathrm{N}$

If yes, state ward(s) and date(s) 
Previous admissions to $\mathrm{CMH}$ in preceding year? $\mathrm{Y} / \mathrm{N}$

If yes, state ward(s) and date(s): 1

2 .......................................... 3

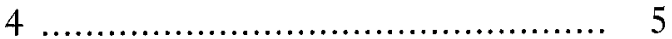

Admission to other hospital/institution in last 12 months? $\mathrm{Y} / \mathrm{N}$

If yes, state place(s) and date(s): 1

2 .............................................. 3

4 ........................................ 5

Any surgical procedure in the last twelve months? $\mathrm{Y} / \mathrm{N}$

If yes, state what and where carried out

Is the patient catheterised? $\mathrm{Y} / \mathrm{N}$

If yes, was that before admission? $\mathrm{Y} / \mathrm{N}$

Are there any skin breaks? $\mathrm{Y} / \mathrm{N}$

If yes, state type, site and acute/chronic

1

2

3

4

5

6

Which, if any, were present on admission? 